\title{
FOETAL MONITORING DURING GENERAL SURGERY: A CASE REPORT
}

\author{
M.J. DOUglas
}

IT Is NOT UNCOMMON for pregnant women to undergo general surgical procedures. This is a report of the continuous monitoring of the foetal heart before, during, and after operation in a woman who was 27 weeks pregnant, using a Doppler apparatus.

The patient was a 20 -year-old white female, nullipara, gravida 2 admitted to hospital at 26 weeks' gestation with a five-day history of leftsided abdominal pain. An obstructed single kidney was diagnosed. Treatment was initiated with ureteral catheter drainage and antibiotics, but surgical intervention was later deemed necessary. Ultrasound examination confirmed the presence of a single footling breech of approximately $\mathbf{2 6}$ weeks' size. The obstetrician managing the pregnancy felt that delay of the operation for one week would give the foetus a better chance for survival if premature delivery should occur.

A left pyeloplasty was seheduled for April 5 , 1978. It was decided to monitor the foetal heart rate continuously throughout the operation using an external monitor. The monitor selected was the Hewlett Packard single beam ultrasound transducer, model 15154A which was attached to a Hewlett Packard monitor, model 8020A. On the morning of the operation the patient was given $20 \mathrm{ml}$ of "Diovol orally and was transported to the operating room on her side. The external monitor was attached in the anaesthetic room. Because the foetus was moving the monitor was placed over the placenta and attached with waterproof tape. The placental site was well below the umbilicus. A blood pressure cuff and electrocardiograph leads were also attached. The table was tilted to the left and the patient was preoxygenated. The intravenous line, previously established on the ward, was checked. The patient was then precurarized with d-tuocurarine $3 \mathbf{m g}$ and after three minutes an induction dose of thiopentone $275 \mathrm{mg}$ was given. The trachea was

* Magnesium-aluminum-simethicone compound (Antteid) (Horner)

M.J. Douglas. M.D., F.R.C.P. (C), Department of Anaesthesia, Vancouver General Hospital, 855 12th Avenue West, Vancouver, B.C. VSZ 1 M9. intubated uneventfully after administration of succinylcholine $100 \mathrm{mg}$ intravenously. The patient was then placed on her right side and the table was flexed. With maximum flexion, slowing of the foetal heart was noted, but this promptly returned to base line as the degree of flexion was decreased. An intra-arterial line was established in the right radial artery to permit continuous monitoring of blood pressure and for blood gas sampling. The results could then be correlated with any signs of foetal distress. Anaesthesia was maintained with halothane supplemented by incremental doses of morphine, and relaxation was achieved using d-tubocurarine. The patient's blood pressure varied between $120 / 80 \mathrm{~mm} \mathrm{Hg}$ pre-induction and $100 / 70 \mathrm{~mm} \mathrm{Hg}$ and the heart rate remained approximately 70 beats per minute. The foetal heart remained stable, except for the previously noted deceleration upon flexion of the table. In particular, no abrupt change was noted with induction of anaesthesia or during surgical manipulation. Two members of the foetal monitoring team were present through the operation to monitor the foetal heart by auscultation.

Two arterial blood gas samples were taken at random during the procerlure. The first showed $\left.\mathrm{cH}^{+} 41.69 \mathrm{nmol} / \mathrm{l}\right](\mathrm{pH} 7.38) \quad \mathrm{Pa}_{\mathrm{O}_{2}} 25.84 \mathrm{kPa}$ (194 mm Hg) $\mathrm{Pa}_{\mathrm{CO}_{2}} 3.59 \mathrm{kPa}(27 \mathrm{~mm} \mathrm{Hg})$ and bicarbonate $16 \mathrm{mmol} / \mathrm{l}$. The second sample was similar to the first.

Relaxation was easily reversed at the end of the procedure with atropine and neostigmine. The patient was transferred to the recovery room awake and comfortable.

Foetal heart rate monitoring was continued in the recovery room. Three hours post-operatively the patient developed uterine contractions. These were controlled with intravenous morphine. On the ward, the foetal heart was monitored on an episodic basis two to three times daily for to to 20 minutes. Heart rate remained normal except for occasional sharp decelerations to 80 per minute lasting 20 seconds, which was thought to be due to cord entanglement.

Three days post-operatively the patient developed some vaginal bleeding and lower abdominal discomfort. Subsequently, she delivered 
a live, immature, female infant weighing 880 grams. The Apgar scores were three at one minute, three at five minutes and six at ten minutes. The infant was transferred to the intensive care nursery but died after a stormy six-week course. The mother had an otherwise normal postoperative course and was discharged.

The value of this monitoring was demonstrated in that a change was picked up when it occurred with positioning of the patient and so could be quickly corrected. Careful attention to positioning, adequate ventilation and oxygenation for the mother, combined with the foetal monitoring made for a smooth anaesthetic course for both foetus and mother.

A search of the literature revealed two articles containing three case histories where foetal monitoring was done on surgical patients. ${ }^{1,2}$ Two of these patients had eye operations and one had a ureterolithotomy. No mention was made of the type of monitor used or the method of attachment.

In view of the current interest surtounding surgery in the pregnant patient, this case is presented to demonstrate the feasibility of monitoring the foetal heart rate in the operating room during certain surgical procedures.

\section{SUMMARY}

A case is reported in which the foetal heart was monitored by a Doppler apparatus during and after an operation on the kidney in a patient who was 27 weeks pregnant. This monitoring proved useful in detecting alterations of foetal heart rate which occurred during positioning of the patient.

\section{RÉSUMÉ}

II n'est pas rare que l'on doive procéder à une chirurgie chez la femme enceinte. Les auteurs rapportent le cas d'une patiente ayant subi une chirurgie (rénale) au cours de sa vingt-septième semaine de grossesse. Le monitoring constant du cour foetal au moyen d'un appareil de Doppler, avant, durant et après l'intervention. s'est avéré fort utile.

\section{REFERENCES}

I. Strong, D.W., Murchison, R.J., \& Lynch, D.F The management of ureteral calculi during pregnancy, Surg., Gynecol., \& Obstet. 146: 604 (1978).

2. Katz, J.D., HoOK, R., \& Barash, P.G. Foetal heart-rate monitoring in pregnant patients undergoing surgery, Am. J. Obstet. Synecol. 125: 267 (1976). 